\title{
Women Empowerment and Modern Contraceptive Use among Married Women in Ibadan, Oyo State
}

\author{
Chimamaka Excellence Uzochukwu ${ }^{1}$, Olufunmilayo Fawole ${ }^{2}$ and Ayo Stephen \\ Adebowale $^{3}$
}

\author{
Department of Epidemiology and Medical Statistics \\ Faculty of Public Health, University of Ibadan, Nigeria. \\ excellent.uzochukwu@gmail.com
}

\begin{abstract}
Nigeria is a male dominant society where most of the household decisions including those related to their female partner's health are taken by men. We examined the relationship between women empowerment and Modern Contraceptives (MC) use in Ibadan, Nigeria where such studies is yet to be documented. Cross-sectional survey design involving both qualitative and quantitative was used to examine 597 women from two selected LGAs in Ibadan. Data were analyzed using Chi-square and logistic regression models (alpha $=0.05)$. Mean age of the women was $33.0 \pm 6.7$ years, $44.4 \%$ had secondary education, $32.2 .0 \%$ was highly empowered and $69.5 \%$ used MC. Injectables (35.1\%) were the commonest $M C$ method currently used. There was an increase in use of $M C$ as the level of empowerment increased, however the level of education was found to be strongly related to $M C$ even after controlling for other factors. Empowering women through education will promote the use of $M C$ in Nigeria.
\end{abstract}

Keywords: Women empowerment, Modern contraceptive, Nigeria, Ibadan, male dominant

\section{Introduction}

In the African context, independent decision making by women on matters pertaining to their health and other life courses is uncommon. Husbands are known to be the decision makers and in most situations women are expected to be seen and not heard. The African tradition plays an important role in this regard. The International Conference on Population and Development Program of Action and Millennium Development Goals had focused the attention of the global community on the need for gender equality and equal opportunities for both men and women (ICPD, 1994; UN, 2002). Consequently, the issues on women empowerment remain important discourse in all parts of the World particularly in sub-Saharan African countries where cultural laws favor men than women in some traditional settings in the region. Empowerment is multi-dimensional "and it is about the extent to which some categories of people are able to control their own destinies, even when their interests are opposed by those of other people with whom they interact" (Uphoff, 2005). The World Bank defines empowerment as the "expansion of freedom of choice and action to shape one's life" (Narayan, 2002). Relating these definitions to women, empowerment therefore is improving the ability of women to access the constituents of development in particular health, education, earning opportunities, rights and political participation (Duflo, 20I2). Studies have been conducted to determine if women empowerment influenced contraceptive uptake in high income countries (Ushma et .al, 2012, upahhyay et .al, 2010 and Sunday et.al 20I3), However much is yet to be known on that context in sub Saharan African particularly in Nigeria. Women empowerment influences women's attitude towards their health, as well as their children's health. Contraceptive use is one of the way to prevent unwanted pregnancy, maternal mortality and unsafe abortions, it is also a panacea to high fertility, sexually transmitted infections (STIs) including HIV/AIDS (FMOH, 200I). Many low income countries in sub Saharan Africa have high fertility, STIs and maternal mortality as major challenges requiring urgent attention (Boniface et.al 2006). For example, maternal mortality rate in Nigeria is the highest in Sub-Saharan Africa and the second highest in the world (WHO, 2005). With women empowerment, the odds of a woman using contraceptives is expected to increase (NDHS, 20I3)

Nigeria with the estimated population of $178,516,904$, contributes $2.4 \%$ of the world's population with Total Fertility Rate (TFR) of 5.5 and growth rate of $3.0 \%$ (NPC - and ICF Macro USA, 2013, Population Reference Bureau, 20I5). Persistent high fertility in Nigeria is still a public health problem 
and has remained a concern to researchers going by its adverse effect on population growth and national development. The prevalence of contraceptive use among women of reproductive age in Nigeria is 15\%, whereas $72 \%$ of these women know of at least one contraceptive method, indicating that knowledge of contraceptive is yet to translate to use (NPC and ICF Macro USA, 2013). These have implications for maternal and child health. For instance, the infant mortality rate in Nigeria is $75 \%$ and maternal mortality ratio is 550 per 100,000 of women (Population Reference Bureau, 2015). The high infant mortality rate, maternal mortality ratio and fertility rate pose threats to the population growth of the country. Thus, increasing the uptake of modern contraceptive method has the impetus to check fertility and mortality because sustaining the current population growth rate will hinder development and the attainment of health goals in the sub-Saharan Africa region. Ibadan community is one of the traditional cities in Nigeria where cultural values are still very relevant to decisions on life and daily courses. Most household decisions are taken by men even among highly educated couples. Household decision on contraceptive use remains a problem in the community. Thus, studies that investigate the relationship between women empowerment and modern contraceptive use are important in lbadan.

A number of factors have been found to be responsible for persistent high fertility rate in Nigeria. One of the most important factors identified is contraceptive use (Olugbenga-Bello, 20II, DHS, 2013). More recently, women empowerment has been found to be important determinant of contraceptive use (Mekonnen, et al, 20/3). For instance, a woman who is empowered stands a better chance of making good health decisions that can improve her wellbeing including her health seeking behavior (Olugbenga - Bello et al 201I). Unfortunately, women are the persons who bear the burden of unplanned and unwanted pregnancies but are often unable to make decisions on their own or their families' health (Mekonnen et al, 20I3). For instance, a woman who is empowered stands a better chance of making good health decisions that can improve her wellbeing including her health seeking behavior (Olugbenga - Bello et al 20ll). Therefore this study examined the association between women empowerment and modern contraceptive use in Ibadan, a traditional society in the south - west region of Nigeria.

\section{Literature review}

Empowerment right from the ancient times means 'to invest with authority'. This definition was later reframed to mean 'to enable or permit'. This idea emerged from the discourse on human development that came into prominence after the 1980's (Tulika, 2002), but gained more attention in population research following the International Conference on Population and Development (ICPD, 1994). In the last few years women empowerment has been a focus of development effort worldwide. Researchers have synthesized existing findings on women empowerment and described how it has influenced international development in the developed countries (Ushma et al, 20/2). Gender based power in sexual relationships has been identified as an important determinant of reproductive health and as being responsible for the wide gap between levels of decision making power and gender equitable attitudes (Blanc et al, 200I). Kishor and Subaiya (2008) reported that gender equality was a means of improving women's status, family planning use and economic growth world-wide.

Research primarily focused on Asia have found women empowerment to be associated with contraceptive use (Woldemicael 2009), lower fertility (Hindin, 2000), and longer birth intervals (Upadhyay and Hindin, 2005). Very few studies on women empowerment have been carried out in sub-Saharan Africa. The few available studies show that gender equity at the community level affected reproductive behavior, especially the desire for more children and contraceptive use. Also, individual women's empowerment domain had the strongest impact on reproductive behavior in communities with lower levels of gender equity (Kritz et al, 2000). Other studies in Africa, used house hold decision making or education alone as a measure for women empowerment.

Women empowerment can be measured with different indicators, the choice depends on the environment and location of the study. A study carried out in Uganda measured women empowerment with household wealth, education and the woman's stand on refusal of sexual intercourse with her husband (Asiimwe, Madugga \& mushomi 20I3). If women can make decisions on their own health and can contribute to decisions taken at home, this suggests that they should be able to make use of any contraceptives they desire or voice their own opinion on issues of family planning. When there is equilibrium of power in sexual relationships there would be positive reproductive health outcomes

Some researchers have tried to determine he association between women empowerment and contraceptive use (Blanc, 2002, Palamuleni 2014; Ushma et al, 20/2). In Egypt, a strong association between women empowerment and contraceptive use was observed between women who had freedom of movement or contributed to decision 
making in the home (Al Riyami et al, 2004). In a study conducted in Ethiopia women empowerment was discovered to be a determinant of contraceptive use (Mekonnen et al., 20I3). Another study carried out in four countries in sub-Saharan Africa found that only Uganda was found an association between all dimensions of women empowerment and female method of contraception (Mai Do and Nami Kurimoto, 20I2).

In many developed countries there have been increases in modern contraceptive use over the years. In Africa, modern contraceptive is more common among the educated and the wealthy compared to the uneducated and the poor (Jimmy et. al 20I3) the study by Olugbenga - Bello (20II), found a high prevalence of contraceptive use in a state in south west Nigeria as a result of high availability and affordability. This result is in contrast to findings from most states in Nigeria where low prevalence of contraceptive use were reported. According to Monjok (2010), more than $60 \%$ of women with unplanned pregnancy were not using contraceptives which has led to high fertility rate, maternal mortality, infant and neonatal mortality.
Nigeria is a religious country. Religion influence behavior including reproductive health practices. Similarly, religion has a great influence on contraceptive use (Oye - Adeniran, 2005). Embedded in the culture, as a male dominant society, most decisions including those that have to do with a woman's health is taken by men. So its unsurprising that single women are more likely to use modern contraceptives than the married ones (Oye Adeniran, 2005).

\section{Conceptual Framework for Women} Empowerment and Modern Contraceptive Use

The conceptual framework as indicated in the figure below shows the interrelationship between the outcome variable (modern contraceptive use) and the independent variables. The sociodemographic factors like education, age, religion and occupation have direct or indirect influence on the domains of women empowerment and modern contraceptive use. The cultural believes and ethnicity also influence women empowerment which in turns influence the use of modern contraceptive. These have been ascertained in the previous studies (Mai Do and Nami Kurimoto, 20I2).

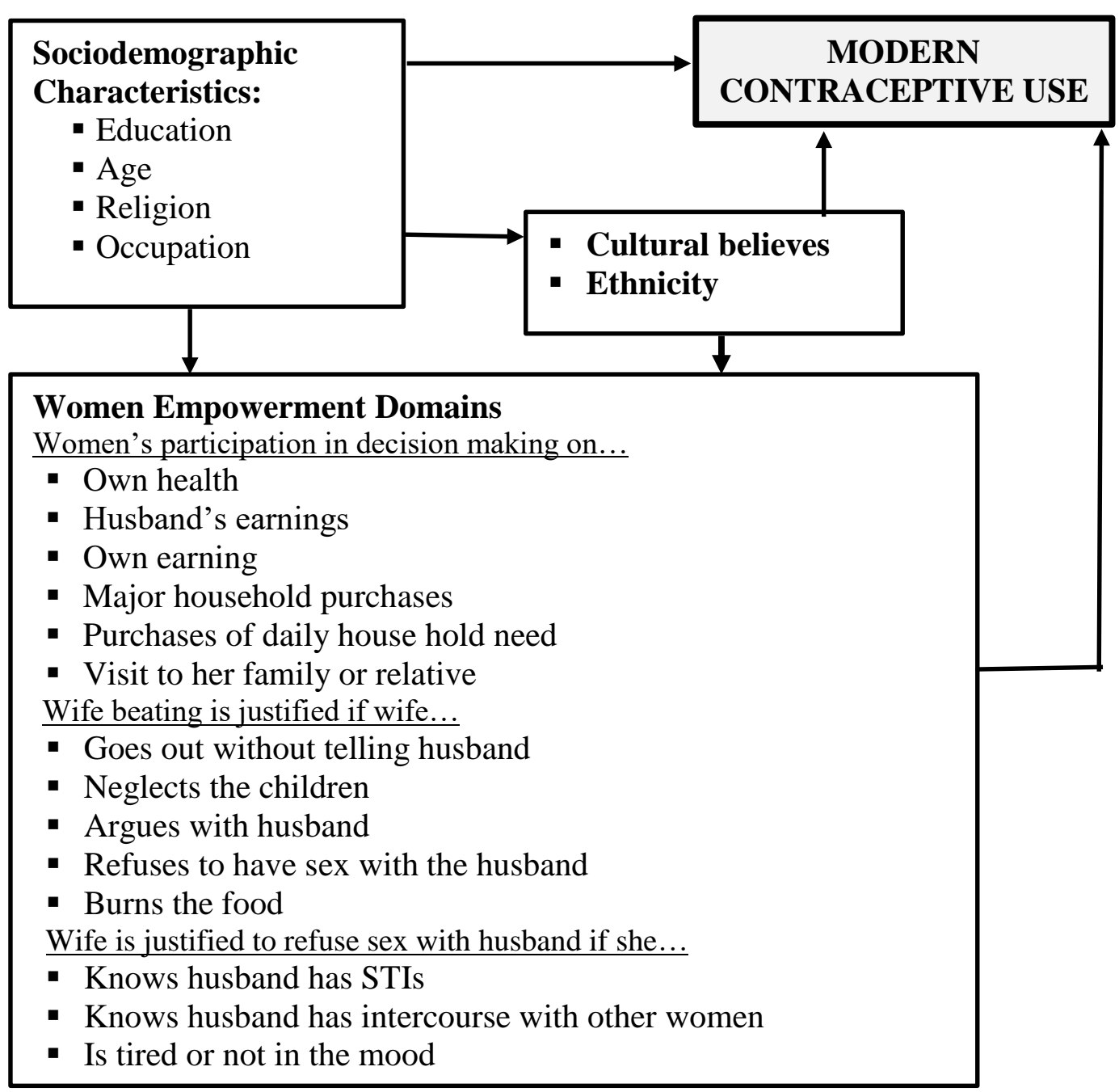




\section{Method}

\section{Study area/ Background setting}

The study was carried out in lbadan, the capital city of Oyo State. Ibadan is the third largest metropolitan city after Lagos and Kano with an estimated population of 2.95 million inhabitants. It is the largest metropolitan geographical area in Nigeria (NPC, 2013). It has II Local Government Areas (LGAs) which are classified into Urban (5) and semi-urban (6). The two randomly selected LGA for this study were Ibadan North East and Egbeda. Ibadan North East is an urban LGA, while Egbeda is semi-urban. These LGAs comprise of multi-ethnic groups but are dominated by the Yoruba speaking people. Ibadan North East and Egbeda LGAs estimated population for the year 2014 of women of reproductive age were 94,979 and 80,943 respectively. Women in these LGAs are mostly traders and civil servants (Oyo State Ministry of Health, 20I4).

\section{Study population and sampling procedures}

The study population was married women of reproductive age. Quantitative and qualitative methods were implored for this research; a five stage sampling technique was adopted for the selection of women for the quantitative data. At the first stage, two LGAs were randomly selected from the eleven

LGAs in Ibadan; one from the urban LGAs and the other from the semi-urban LGAs. Out of the twelve wards in each of the selected LGA, three wards each were selected by simple random sampling to make a total of six wards. Two communities were randomly selected by balloting from each ward to make a total of 12 communities in all. In each community, households that had at least one eligible respondent were listed and this constituted the sampling frame for the study thereafter, 48 respondents were selected from each chosen community using systematic random sampling technique thus making a total of 576 respondents. However, in a household where more than one eligible respondent was identified, the respondent was chosen using lottery method.

A minimum sample size of 576 was computed based on prevalence of $37.4 \%$ (NDHS, 2013) and used for the study but the size was increased to 597 to account for non-response. Focused group discussion was also carried out at the study area, using a well-structured FGD guide, with consents of about 12 respondents within 28-45 years of age, most of the women were self-employed, and comments of all respondents were properly transcribed and analyzed using thematic approach.

\section{Measurements}

Dependent variable: The dependent variable was current use of contraceptives. Sexually active women were asked if they used any contraceptive method 34 weeks preceding the study. Persons, who had used, were asked the type they used. Responses were coded into three categories namely: not using any method, using at least a traditional and using at least a modern method.

Independent variable: Women empowerment was measured using the listed indicators below;

Women's participation in household decision making: Four variables were used to measure women's role in house hold decision making, these were; participation in her own health care decisions, participation on major household purchase decisions, person who takes decisions on visits to family and relatives, involvement in decisions on daily household purchases.

Women's attitude towards wife beating: Women were asked if husbands were justified to beat his wife to following five acts namely, if she:- goes out without telling her husband, neglects the children, argues with her husband, and refuses to have sex and if she burns food.

Women's attitude towards sex: Women were asked if they are justified to refuse sex with husband if: - she is aware husband has sexually transmitted disease, if husband has intercourse with another woman, if she is tired or not in the mood.

Based on the responses of women to the questions in the domain, an aggregate score $x$ was generated (maximum score $=20$ ) for each woman and $\mathrm{x}$ was disaggregated into three categories using $50^{\text {th }}$ and $75^{\text {th }}$ percentiles as follows;

Women empowerment level

$$
=\left\{\begin{array}{l}
\text { Highly empowered if } 75 \% \leq x \leq 100 \\
\text { Fairly empowered if } 50 \% \leq x<75 \% \\
\text { Poorly empowered if } 0 \% \leq x<50 \%
\end{array}\right.
$$

\section{Data Analysis}

Data were analyzed using Chi-square and logistic regression models $(a l p h a=0.05)$. The Chi-square tests were performed to examine the association between contraceptive use and women empowerment. Other independent variables such as education, age, religion were also tested for association with contraceptive use. The multivariate analysis was performed to identify the sociodemographic predictors of modern contraceptive use. Thematic approach was used to analyze the qualitative data. 


\section{Results}

The mean age of the respondents was 33.0 \pm 6.7 and $50.7 \%$ were Muslims. Most of the women were Yoruba's (94.5\%). Secondary education was the highest reported level of education attained by the respondents $(44.4 \%)$ with $(8.8 \%)$ having no formal education. Most $(76.1 \%)$ of the respondents were traders.

Majority of the women (81.0\%) were currently using a contraceptive method, with $69.7 \%$ using a modern method. Among the contraceptive methods listed, $71.0 \%$ were aware of female sterilization, but none had ever used the method. About $98.3 \%$ were aware of injectables and $35.1 \%$ had ever used the method. Also, 91.3\% were aware of implants but only $12.1 \%$ had ever used it. This pattern was in agreement with responses from the FGDs.

The data in table 2 showed that $32.2 \%, 55.5 \%$ and $12.3 \%$ were highly, fairly and poorly empowered respectively. A higher portion (74.2\%) of those highly empowered used modern contraceptives compared to $64.8 \%$ of those who were poorly empowered. About $70.0 \%$ of women aged 25-34 years were currently using modern contraceptives compared to $64.8 \%$ of women aged 15-24 years. More traders $(72.6 \%)$ were also found to be using modern contraceptive than civil servants (53.4\%). Education was the only predictor of modern contraceptive use with the likelihood of using modern contraceptive found to be $2.6(C . I=I .2-5.8, p=0.02)$ times higher than the women with no formal education. Empowerment was a significant predictor of modern contraceptive use but increasing level of empowerment was found to be protective of modern contraceptive use.

FGD revealed that the major reason for not using contraceptives was fear of side effect. As by one respondent mentioned:-

"I don't use contraceptive because it deforms people it make them get fat and have big stomach" (FGD, age 40).

Most of the women who used contraceptive said their husbands were aware that they are using it, while some said their husbands were not aware. A respondent said

“My husband doesn't like it but I don't want to get pregnant so I use contraceptive so I will not get pregnant every time (FGD, age 40 ).

But some said,

"If your husband don't know about it that means the woman is having an extra marital affair".

Respondents' response to Decision making

Most of the women interviewed were traders and earned a living. As regards decision making on how that money is spent, most of the respondents, said they decided on how the money they made was spent. Two of the respondents said

"I decide on how the money I make is spent because I'm a business woman I do not wait for my husband to tell me when I should go to the market so I say how I spend my money" (FGD age 35) and another respondent said

"I work to have money of my own; my husband has his own money so I use my own the way I like when I have problems to solve (FGD, age 25).

\section{Daily house hold purchases}

Majority of the women believed it was the woman's duty to ensure that groceries and other small items at home are available, one of the women said

"we have businesses and work so that we will use the money to buy things in the house and also help our children" another said if my husband is in the house I would ask him for money of we would talk how we shall buy the things" (FGD, age 33).

Another respondent;

"Since what my husband is trying to do is to build the house I can help him if I can't" (FGD, age 28).

Domestic violence was not condoned by any of the women interviewed, they all said there was no justification for a man to hit a woman, a respondent said

"I am not a baby if I do what is wrong my husband should tell me and let us settle the matter" (FGD, age 39).

\section{Attitude towards sex}

All the women agreed that if a man has a sexually transmitted disease (STI) they would not have sexual intercourse with him. A respondent said

"Ah I don't want to die oo! I will say No!" (FGD, age 38 ).

However, not having sexual intercourse with husband, because of fatigue or not being in the mood was not supported I by the women. One respondent said

"If you say NO, you will pack your load out of the house"

But if the man is having an extra marital affair some said they would not agree to have sex with him. A respondent said

"It is not possible that is the end, he should go and meet his woman friend" (FGD, age -) another said "that time is when I would do my best in bed to keep my husband" another said "if he is doing his duty and is having affair outside I can still manage that and will still sleep with him to save my family" (FGD, age 30).

Emerging from the discussion it was evidence that women would only refuse their husbands sexual 
intercourse if he had a STI. Tiredness or not in the mood was not an acceptable reason for refusal. However, opinions were divided when husband had extra marital relationships or was irresponsible.

\section{Discussion}

Women empowerment is one of the issues of global importance in contemporary times. This is because of its benefits in shaping the career goal of women and their health. It is thus believed that if a woman is empowered, she would be able to take some decisions that can positively influence their life without consulting any person. Unfortunately, in Ibadan, a traditional community where people still hold onto their traditional and cultural identities, women particularly married women may find it difficult to take some decisions on their own; in this community it is rare for a married woman to take important decisions particularly on health issues without prior discussion with the husband. The decision to use contraceptive by a woman in this setting may be a function of her level of empowerment. This study determined the association between empowerment and contraceptive use among women of reproductive age in Ibadan. It also assessed the prevalence of contraceptive use among the women.

A prevalence of modern contraceptive use of $69.5 \%$ was found in this study; this prevalence is in agreement with studies carried out in South Western Nigeria where a prevalence of $66.3 \%$ was reported (Olugbenga-Bello Ai et al., $20 \mathrm{II}$ ) and $73.3 \%$ Odusina et al (2012). Although, the higher prevalence found is much higher than the national prevalence rate of $10 \%$ (NPC and Macro International, 2013) this difference can be explained by high level of economic independence and knowledge of contraceptives among our respondents. The study area is a metropolitan city where the prevalence of modern contraceptive use is the third highest in the country with the prevalence of modern contraceptive in South west and Oyo state, $25 \%$ and $24.4 \%$ (NDHS 20I3). In addition, the prevalence of unmet need of contraception we obtained was low (19.0\%). This finding is consistent with the unmet need for modern contraceptive found in a similar study conducted by Olugbenga-Bello et al. (20II)

The study shows that the contraceptive method known and currently used by most respondents was the injectables. A possible explanation for this is that the method could be used without informing sexual partners, unlike female condom, pills, and IUD which require partner's cooperation or may be noticed by partners when in use. Also, the excessive bleeding which sometimes occurs from the use of IUCD can unveil the use of the method to the partners.
However, our finding that injectables was the most reported contraceptive method currently used is in line with the outcome from a national survey data collected recently in Nigeria.(NPC and Macro International, 20/3)

One of the limitations of the study was its cross sectional design hence temporal relationship and causality could not be determined and established respectively. Also, measure of empowerment could have been subject to information bias as respondents might have given socially desirable responses on their decision making power.

\section{Conclusion}

There was no significant link between women empowerment and the use of modern contraceptive among married women in Ibadan. Instead, level of educational attained remains an important factor. Fear of adverse effects and partner's lack of support were the main reasons found to deter women from using modern contraceptive. Thus improving women's school enrolment and education may have great influence on modern contraceptive uptake in Ibadan. Heath education on modern contraceptive use should also target men in terms of their support and contraceptive choices in anticipation for removing the fear of side effect perception of modern contraceptive among women.

\section{References}

Asya A. Al-Riyami, Bsc, Phd, Mustafa Afifi, 2003 Women Empowerment And Marital Fertility In OMAN Saudi Med Journal ; Vol. 24 (7)

Blanc, A.K., 200I. The Effect of Power in Sexual Relationships on Sexual and Reproductive Health: An Examination of the Evidence. Studies of. Family. Planning. 32, I89-213

Duflo, Esther. 2012. "Women Empowerment and Economic Development." Journal of Economic Literature, 50(4): 105 I-79.

Emmanuel Monjok, Andrea Smesny, John E Ekabua, E James Essien 2010 "Contraceptive practices in Nigeria: Literature review and recommendation for future policy decisions "open access journal 5 May Volume:I Pages 9-22

Federal Ministry of Health 200I

Hindin, M.J. 2000. "Women's Autonomy, Women's Status and Fertility-Related Behaviour In Zimbabwe." Population Research And Policy Review 19:255-282.

International Conference on Population and Development (1994). Cairo.

John Bosco Asiimwe, Patricia Ndugga, John Mushomi 2013. Socio-Demographic Factors Associated With Contraceptive Use Among Young Women In Comparison With Older Women In Uganda, 
Journal Of Humanities And Social Science Invention International Journal Of Humanities And Social Science Invention ISSN : 2319 - 7722, ISSN (Print): $2319-7714$

Kabeer, Naila (2002). "Resources, Agency, Achievements: Reflections on the Measurement of Women's Empowerment". Sida Studies No. 3. (ISBN 9I-586-8957-5.) Retrieved From:Http:/Www.Sida.Se/Shared//sp/Download.]

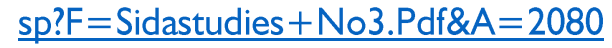

Kishor, S., Subaiya, L., 2008. Understanding Women's Empowerment: A Comparative Analysis Of Demographic and Health Surveys (DHS) Data. Comparative Report. Macro International Inc., Calverton, Http:/Www.Measuredhs.Com Pubs/Pdf/CR20/CR20.Pdf

Mai Do And Nami Kurimoto, 2012 Women's Empowerment And Choice Of Contraceptive Methods In Selected African Countries Journal Of International Perspectives On Sexual And Reproductive Health March Vol 38,(I),

Malhotra, A., Schuler, S.R. And Boender, C. (2002) Measuring Women's Empowerment as a Variable in International Development. Paper Commissioned By the World Bank, Gender and Development GroupAvailable Athttp://Siteresources.Worldbank.Org/INTGEND ER/ Resources/Malhotraschulerboendr.Pdf.

ఏimmy Ronald Andi, Robert Wamala, Bruno Ocaya, and Allen Kabagenyi " Modern contraceptive use among women in Uganda" An analysis of trend and patterns (I995-20II) PMC 2014 Dec 18.

Mekonnen Tadesse, Habtamu Teklie, Gorfu Yazew and Tesfayi Gebreselassie 2013. Women's Empowerment as a Determinant of Contraceptive Use in Ethiopia. Further Analysis of The 201I Demographic and Health Survey. DHS Further Analysis Reports No. 82. Calverton, Maryland, And USA: ICF International

M.E Palamuleni, and A.S Adebowale 2014 Women empowerment and the current use of long acting and permanent contraceptive: Evidence from 2010 Malawi Demographic and Health Survey, Malawi Medical Journal; 26 (3): 63-70.

Mornica Das Gupta 2013 "Women Empowerment And Fertility Presented At The UN Expert Group Meeting "Fertility Changing Population Trends And Development: Challenges And Opportunities" New York 2I-22 October National population Commission 2013.

Narayan D, Ed., Empowerment and Poverty Reduction: A Sourcebook, Washington, DC: World Bank, 2002.
Nwachukwu, Ike. O, O, Obassi (April 2008) "Use Of Modern Contraceptive Method Among Rural Community In Imo State Nigeria, African Journal Of Reproductive Health I2 (I): I0I-I08.

Olugbenga-Bello AL, Abodunrin OL, Adeomi AA.: 2011 Contraceptive Practices Among Women In Rural Communities In South-Western Nigeria. Global Journal of Medical Research Vol I I (2),

Oyo state Ministry of Health 2014.

PRB (20I2). World Population Data Sheet by Population Reference Bureau

PRB (20|3). World Population Data Sheet by Population Reference Bureau

Stephen A. Adebowale, Ikeola Adeoye and Martin E. Plamuleni (20/3). Contraceptive Use among Nigerian Women With No Fertility Intention: Interaction Amid Potential Causative Factors. African Population Studies October 2013; 27, No 2.

Upadhyay, Ushma D. and Deborah Karasek. 2010. "Women's Empowerment and Achievement Of Desired Fertility In Sub-Saharan Africa." DHS Working Papers No. 80. Calverton, Maryland, USA: ICF Macro.

Ushma D. Upadhyay, Jessica D. Gipson (20|4), Mellissa Withers, Shayna Lewis, Erica J. Ciaraldi , Ashley Fraser, Megan J. Huchko, Ndola Prata "Women's Empowerment And Fertility: A Review Of The Literature" Elsevier Journal Of Social Science \& Medicine II 5 - I 20.

Ushma D. Upadhyay, 2010 "Women's Empowerment and Achievement of Desired Fertility in Sub-Saharan Africa" DHS Working Papers No 80.

Ushma D. Upahyay and Deborah Kaasek 2012 Womens Empowerment And Ideal Family Size An Examination Of DHS Empowerment Measures In Sub-Saharan Africa Vol 38, Num 2, June.

Uphoff, N. (2005) Analytical Issues In Measuring Empowerment At Community And Local Levels, In: D. Narayan (Ed.) Measuring Empowerment Cross Disciplinary Perspectives, (Washington, D.C The World Bank.) 219-246.

UNITED NATIONS 2002.

Woldemicael, G. 2009. Women's Autonomy and Reproductive Preferences in Eritrea. J Biosoc Sci $4 I(2):|6|-|8|$

World Health Organization 2005 
Table I Calculation of women empowerment score index.

\begin{tabular}{|c|c|c|}
\hline Women empowerment indicators & Scores & MS \\
\hline Women's participation in decision making on. & & \\
\hline Own health & $\begin{array}{l}\text { Someone else }=0 \text {; Mainly husband }=0 \text {; Wife } \\
\text { and husband jointly }=1 ; \text { Mainly wife }=2\end{array}$ & 2 \\
\hline Husband's earnings & $\begin{array}{l}\text { Someone else }=0 \text {; Mainly husband }=0 \text {; Wife } \\
\text { and husband jointly }=1 \text {; Mainly wife }=2\end{array}$ & 2 \\
\hline Own earning & $\begin{array}{l}\text { Someone else }=0 \text {; Mainly husband }=0 \text {; Wife } \\
\text { and husband jointly }=1 \text {; Mainly wife }=2\end{array}$ & 2 \\
\hline Major household purchases & $\begin{array}{l}\text { Someone else }=0 \text {; Mainly husband }=0 \text {; Wife } \\
\text { and husband jointly }=I \text {; Mainly wife }=2\end{array}$ & 2 \\
\hline Purchases of daily house hold need & $\begin{array}{l}\text { Someone else }=0 ; \text { Mainly husband }=0 ; \text { Wife } \\
\text { and husband jointly }=1 ; \text { Mainly wife }=2\end{array}$ & 2 \\
\hline Visit to her family or relative & $\begin{array}{l}\text { Someone else }=0 \text {; Mainly husband }=0 \text {; Wife } \\
\text { and husband jointly }=1 ; \text { Mainly wife }=2\end{array}$ & 2 \\
\hline Wife beating is justified if wife... & & \\
\hline Goes out without telling husband & Justified $=0 ;$ Not Justified $=1$ & I \\
\hline Neglects the children & Justified $=0 ;$ Not Justified $=1$ & I \\
\hline Argues with husband & Justified $=0 ;$ Not Justified $=1$ & I \\
\hline Refuses to have sex with the husband & Justified $=0 ;$ Not Justified $=1$ & l \\
\hline Burns the food & Justified $=0 ;$ Not Justified $=1$ & 1 \\
\hline Wife is justified to refuse sex with husband if.. & & \\
\hline $\begin{array}{l}\text { I. She knows husband has sexually transmitted } \\
\text { diseases }\end{array}$ & Justified $=I ;$ Not Justified $=0$ & I \\
\hline $\begin{array}{l}\text { m. Knows husband has intercourse with other } \\
\text { women }\end{array}$ & Justified $=I ;$ Not Justified $=0$ & I \\
\hline Is tired or not in the mood & Justified $=I ;$ Not Justified $=0$ & I \\
\hline Total Score & & 20 \\
\hline
\end{tabular}

MS: Maximum Score

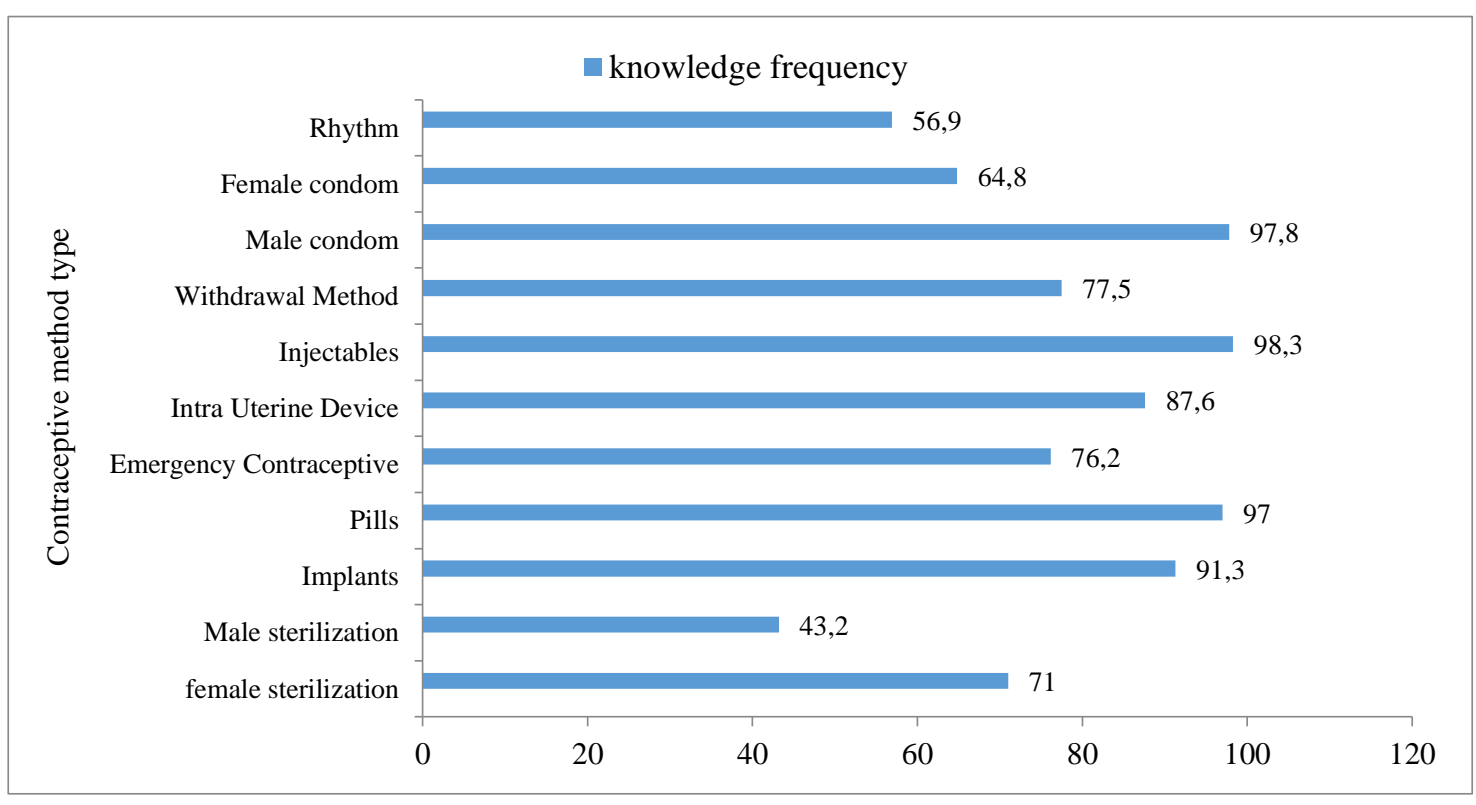

Figure I: Bar chart illustrating Distribution of Women by awareness of Contraceptive 
Table 2: Socio-demographic characteristics by modern contraceptive use

Background characteristics

Modern

Contraceptive Use

P.value

Yes (\%) $\quad \mathrm{Nn}(\%)$

\begin{tabular}{|c|c|c|c|c|}
\hline \multirow{2}{*}{\multicolumn{5}{|c|}{ Age }} \\
\hline & & & & \\
\hline $15-24$ & $44(64.8)$ & $19(30.3)$ & 0.002 & 0.99 \\
\hline $25-34$ & $196(69.8)$ & $85(30.2)$ & & \\
\hline $35-49$ & $174(69.6)$ & $76(30.4)$ & & \\
\hline Religion & $198((67.8)$ & $94(32.2)$ & 0.87 & 0.35 \\
\hline Christian & $214(71.3)$ & $86(28.7)$ & & \\
\hline \multicolumn{5}{|l|}{ Muslim } \\
\hline Ethnicity & $392(69.5)$ & $172(30.5)$ & 0.11 & 0.74 \\
\hline \multicolumn{5}{|l|}{ Yoruba } \\
\hline \multicolumn{5}{|l|}{ Others } \\
\hline \multicolumn{5}{|l|}{ Occupation } \\
\hline Trading & $302(72.6)$ & I $4(27.4)$ & $9.063 * * *$ & 0.011 \\
\hline Fashion designer & $53(64.6)$ & $29(35.4)$ & & \\
\hline \multirow[t]{2}{*}{ Civil servant } & $26(53.1)$ & $23(46.9)$ & & \\
\hline & & & 6.210 & 0.102 \\
\hline Level of education & $42(80.8)$ & $10(19.2)$ & & \\
\hline No formal & $129(7 \mid .2)$ & $5 I(28.3)$ & & \\
\hline Primary & $182(69.2)$ & $81(30.8)$ & & \\
\hline Secondary & $60(61.9)$ & $37(38.1)$ & & \\
\hline \multicolumn{5}{|l|}{ tertiary } \\
\hline \multicolumn{5}{|c|}{ Women Empowerment } \\
\hline Poorly empowered. & $46(64.8)$ & $25(35.2)$ & 3.211 & 0.201 \\
\hline Fairly empowered & $217(67 \%)$ & $104(32.4)$ & & \\
\hline Highly .empowered & $138(74.2)$ & $48(25.8)$ & & \\
\hline
\end{tabular}

Table 3: Logistic regression of Contraceptive use on Socio-Demographic characteristics of Respondents and women Empowerment, unadjusted.

\begin{tabular}{llll} 
Variable & Odds ratio & $95 \% \mathrm{Cl}$ OR & P value \\
\hline Empowerment & & & \\
Poorly(ref) & $\mathrm{I}$ & & \\
Fairly & 0.88 & $0.5 \mathrm{I}-1.5 \mathrm{I}$ & 0.65 \\
Highly & 0.64 & $0.36-1.15$ & 0.14 \\
& & & \\
Age(years) & $\mathrm{I}$ & $0.554-1.821$ & 0.99 \\
I5-24(ref) & 1.004 & $0.554-1.846$ & 0.97 \\
$25-34$ & $1.01 \mathrm{I}$ & & \\
$35-49$ & & & \\
Education & & & 0.192 \\
None (ref) & $\mathrm{I}$ & $0.775-3.558$ & 0.097 \\
Primary & 1.660 & $0.894-3.909$ & 0.020 \\
Secondary & 1.869 & $1.161-5.777$ & \\
Tertiary & $2.590 * * *$ & &
\end{tabular}


Table 4: Logistic Regression of Contraceptive use on Education after adjusting for Age, Women Empowerment and Occupation.

Variable

Empowerment

Poorly(ref)

Fairly

Highly

Age(years)

15-24(ref)

25-34

35-49

Education

No formal (ref)

Primary

Secondary

Tertiary

Occupation

Trading

Tailoring

Civil servant(ref)
Odds ratio I

0.749

0.577

I

1.187

0.974

1

2.235

$2.957 * * *$

$3.433 * * *$

1

0.510

0.669 95\% Cl OR $P$ value

$0.414-1.383 \quad 0.346$

$0.304-1.137 \quad 0.100$

$0.604-2.333$

0.619

$0.478-1.975$

0.943

$0,875-5.706$

0.093

$1.186-7.37 \mid$

0.020

$1.219-9.664$

0.020

$0.245-|.06|$

0.072

$0.287-|.56|$

0.353 